Haya: The Saudi Journal of Life Sciences

Abbreviated Key Title: Haya Saudi J Life Sci ISSN 2415-623X (Print) |ISSN 2415-6221 (Online) Scholars Middle East Publishers, Dubai, United Arab Emirates Journal homepage: https://saudijournals.com/sjls

Original Research Article

\title{
Distribution of Outdoors Mosquito Genera in Six Communities in Ekiti State, Nigeria \\ Olorunniyi O. F*
}

Department of Zoology and Environmental Biology, Ekiti State University, Ado-Ekiti, Ekiti State, Nigeria

DOI: $10.36348 /$ sjls.2020.v05i03.002 $\quad$ | Received: 19.03 .2020 | Accepted: 27.03 .2020 | Published: 30.03 .2020

*Corresponding author: Olorunniyi O. F

\section{Abstract}

Many of mosquito genera are exophagic that bite humans outdoors. Most community members in Nigeria are in the habit of staying outdoors at dusk for relaxation which can expose them to mosquito bites. This necessitated the design of this study with the objectives to examine the distribution of exophagic mosquito genera in six communities in Ekiti State, Nigeria. The communities were selected through a multistage sampling method. Adult mosquitoes were collected outdoors from the six communities by using miniature Centre for Disease Control light traps for twelve months. The collected mosquitoes were sorted into sexes and genera. Data were analyzed by descriptive statistics and chi-square using SPSS. Five hundred and five (505) adult mosquitoes were collected outdoors in the six study communities, females (96.6\%) and males (3.4\%). Mosquito genera collected were Culex (90.5\%), Anopheles (5.3\%) and Aedes (4.2\%). Culex and Aedes Population peaked in October but Anopheles population peaked in July. Availability of mosquito vectors at dusk in these study communities is an indication that the community members could be at risk of mosquito borne diseases.

Keywords: Mosquito, Ekiti, outdoors, mosquito vectors, periurban, rural, culex, aedes, anopheles.

Copyright @ 2020: This is an open-access article distributed under the terms of the Creative Commons Attribution license which permits unrestricted use, distribution, and reproduction in any medium for non-commercial use (NonCommercial, or CC-BY-NC) provided the original author and source are credited.

\section{INTRODUCTION}

Mosquitoes are biting insects of the order Nematocera with about three and half thousand species [1]. They are vectors of many disease causing agents such as viruses, protozoans and filariae [2]. Three major genera that are of medical importance namely, Culex, Anopheles and Aedes are widely distributed in the world [2]. The genus Aedes contains several species that transmit arboviruses, including yellow fever, dengue, chikungunya, Rift Valley fever and Zika viruses. The genus Culex has various species that transmit microfilaria (Wuchereria bancrofti) and flaviviruses while various species of Anopheles transmit malaria parasites (Plasmodium), W. bancrofti and arboviruses [2]. Many of these mosquito genera are exophagic that bite humans outdoors $[2,3]$.

Community people in Nigeria are in the habit of staying outdoors at dusk for relaxation and this habit exposes them to mosquito bites. In a study conducted in six communities in Ekiti State, majority of the community members were said to be staying outdoors at dusk for relaxation before going to bed (Olorunniyi and Idowu, not yet published). The implication of this is that many of these people could be bitten by mosquitoes thereby putting them at the risk of contacting mosquito borne diseases. This necessitated the design of this study with the objectives to examine the distribution of the exophagic mosquito genera in these six communities. The design of this study was to expand the initial work that had been carried out in these six communities on the mosquito avoidance practice (Olorunniyi and Idowu, not yet published). The study areas consisted of periurban and rural communities. Ekiti State is one of the 36 states in Nigeria and it is located in Southwest Nigeria.

\section{MATERIALS AND METHODS Selection of Study Communities}

Six communities were selected through a multistage sampling method [4]. Stage 1 was the selection of all the three senatorial districts in Ekiti State. Senatorial district is a geopolitical division that exists in every state of Nigeria. Each state has three Senatorial Districts and within each of the senatorial district are local government areas (LGAs). Stage 2 was selection of one local government area (LGA) from each of the senatorial district by lottery. Stage 3 involved purposefully selection of one peri-urban 
community and one rural community from each of the selected LGA. The criteria for categorizing the communities into peri-urban and rural were based on the characteristics highlighted by Ayorinde [5] and
Agbodike [6]. The selected communities were Iye, Iyin, Agbado (periurban) Ewu, Eyio and Ilupeju-Ijan (rural). The geographic location of the communities within Ekiti State is shown in Figure-1.

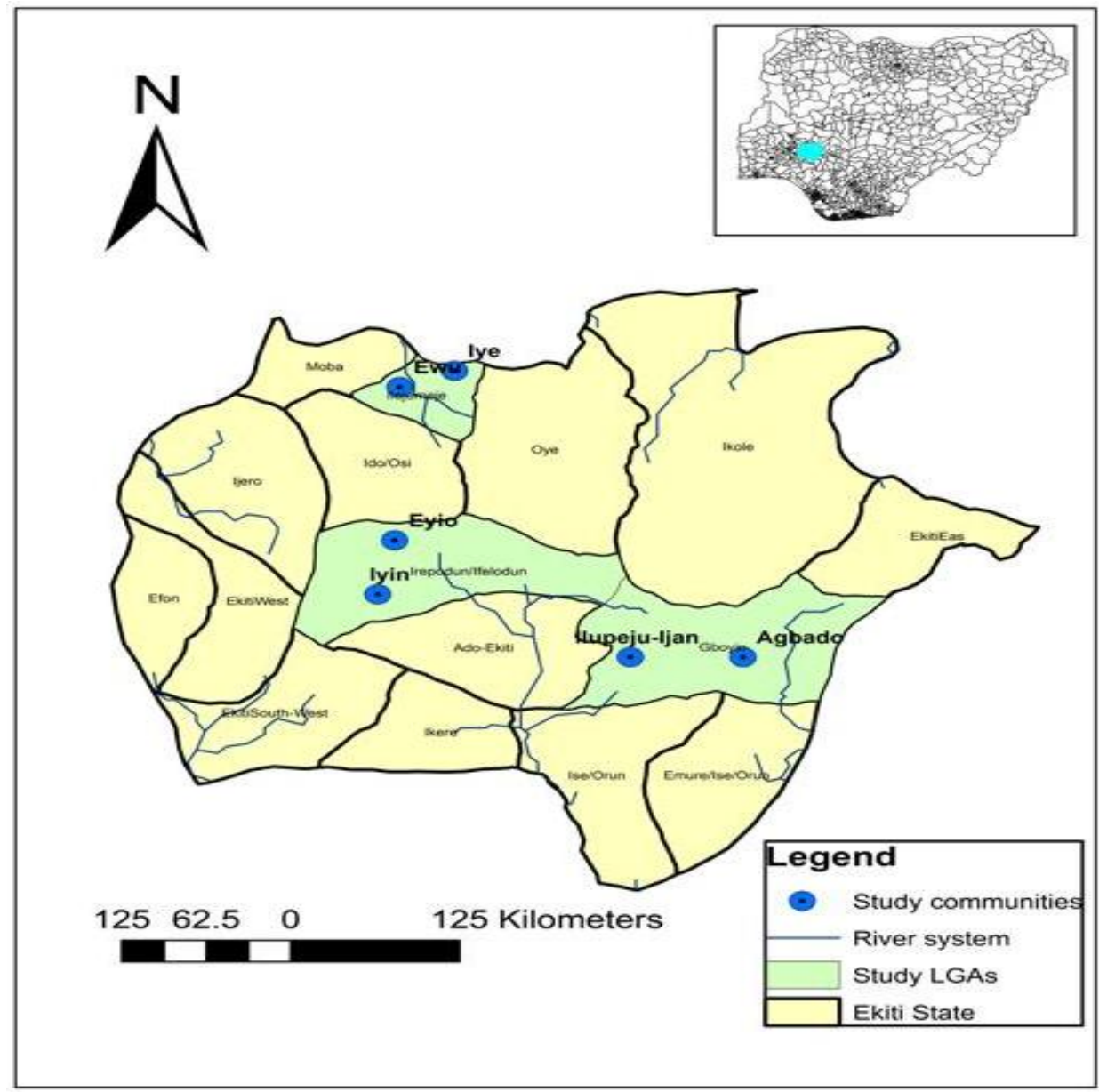

Fig-1: Map of Ekiti State of Nigeria showing the study communities

\section{Collection of mosquitoes in the study communities}

Adult mosquitoes were collected for twelve months from these study communities from July 2017 to June 2018. In each of the communities, collection of mosquitoes was done two consecutive days for each month. In order to have a widely distributed collection of mosquitoes in each community the households within the area were divided into sections to generate sampling frames for the random selection of houses representative of the area. A house was selected in each section of the divisions. Mosquitoes were collected from the selected houses using miniature Centre for Disease Control [CDC] light traps [Model 512; John W. Hock Company, Gainesville, FL, USA]. The miniature CDC light traps were positioned next to a person lying on a bench or sitting down in a resting chair under a net in front of the selected houses at each site. Traps were set at 6:00 PM and removed at 9:00 PM which was the usual time the people in the communities used to stay outdoors for relaxation. The captured mosquitoes were sorted into sexes and genera using morphological keys [7].

\section{Data Analysis}

Data were analyzed with SPSS version 20. Statistics involved were descriptive and chi-square. A probability value [p-value] of $P<0.05$ was regarded as significant for inferential statistics.

\section{RESULTS AND DISCUSSION}

Population of Mosquitoes Collected in the Study Communities

A total number of five hundred and five (505) adult mosquitoes were collected outdoors in the six study communities for twelve months (Table-1). The females were $96.6 \%$ while the males were $3.4 \%$. The higher population recorded in females when compared to the males was due to the nature of the sites where the mosquitoes were collected. The mosquitoes were collected around houses where human beings dwell and female mosquitoes are usually found in such places due to their anthropohilic nature. They search for human blood to nurture their oviposition [8]. Male mosquitoes suck plant juice and therefore may not be found around the human dwelling areas. Mosquito genera collected 
were Culex (90.5\%), Anopheles (5.3\%) and Aedes (4.2\%). Figure-2 shows the population of mosquito genera collected in the respective communities and also when such communities were grouped into two community types (i.e. periurban and rural). The most abundant population of Culex mosquitoes recorded in this study conformed to the result obtained on the study of species composition and distribution of mosquito populations in Ibadan, Nigeria [9]. But the result was contrary to the findings of Amaechi et al., [10] where Anopheles mosquitoes were reported to have a higher population density than Culex. However, the low population of Aedes mosquitoes in this study agrees with their findings. The abundance of Culex in this study is most likely due to the biology of the insect. While Culex can breed in all types of water collections including temporary or permanent stagnant water bodies such as drains, septic tanks, wet pit latrines, organically polluted sites and puddles [11], Anopheles mosquitoes on the other hand breed most often in a natural environment containing clean water which majorly depends on rainfall [12]. This must be the reason why Anopheles population increased during the time of high rainfall which was between June and September and the population peaked at July whereas the population of Culex and Aedes peaked at October (Figure-3). Larvae of Anopheles prefer clear, fresh seepage water in sunlight or partially shaded pools [13]. However, some larvae of Anopheles gambiae s.l. have been reported to be found in organically polluted water containing human faeces, oil from refinery and sewage pond indicating that Anopheles may as well breed in such habitat [14]. Kitching [15] gave some of the breeding sites of mosquitoes. Also, the physico- chemical parameters where mosquito larvae can develop and survive in Nigeria have been given [16, 17]. The low population of Aedes (4.2\%) in this study could not have been unconnected with the time of collection of these mosquitoes and the nature of the communities. Most Aedes mosquitoes are active and bite during the daytime hours and they are mostly found in urban areas [18] whereas the collection of mosquitoes in this study was done at dusk in the periurban and rural areas. There was a significant difference $(P=0.004)$ in the population of the mosquito genera collected across the six study communities (Figure-2a). Although the population of mosquitoes collected was higher in peri-urban than the rural communities but no significant difference $(P=0.435)$ existed in the population of the mosquitoes in the two community types (Figure-2b). The higher in population of mosquitoes recorded in the periurban than the rural communities could be linked with the environmental conditions of the two community types. While most urban and periurban communities in Nigeria are known to have poor drainage system [19] that are capable of providing breeding places for mosquitoes, most rural communities usually lack water drainage system. Generally, mosquito population is usually higher during raining season than dry season in Nigeria [20, 21] which is due to the availability of abundant breeding places. This must be the reason why higher population of mosquitoes was collected during raining season between May to October than during the dry season between November and April in this study (Figure-3). The distribution of the mosquito genera collected across the twelve months in the study communities showed a significant difference $(P=0.001)$.

Table-1: Mosquito genera collected outdoors in the study communities

\begin{tabular}{|l|l|l|l|}
\hline Mosquito genera & Male & Female & Number collected \\
\hline Culex & $13(2.8 \%)^{*}$ & $444(97.2 \%)^{*}$ & 457 \\
& $(76.5 \%)^{* *}$ & $(91.0 \%)^{* *}$ & $(90.5 \%)^{* *}$ \\
\hline Anopheles & $4(14.8 \%)^{*}$ & $23(85.2 \%)^{*}$ & 27 \\
& $(23.5 \%)^{* *}$ & $(4.7 \%)^{* *}$ & $(5.3 \%)^{* *}$ \\
\hline Aedes & $0(0.0 \%)^{*}$ & $21(100 \%)^{*}$ & 21 \\
& $(0.0 \%)^{* *}$ & $(4.3 \%)^{* *}$ & $(4.2 \%)^{* *}$ \\
\hline Total & $\mathbf{1 7}(3.4 \%)$ & $\mathbf{4 8 8}(96.6 \%)$ & $\mathbf{5 0 5}$ \\
\hline
\end{tabular}

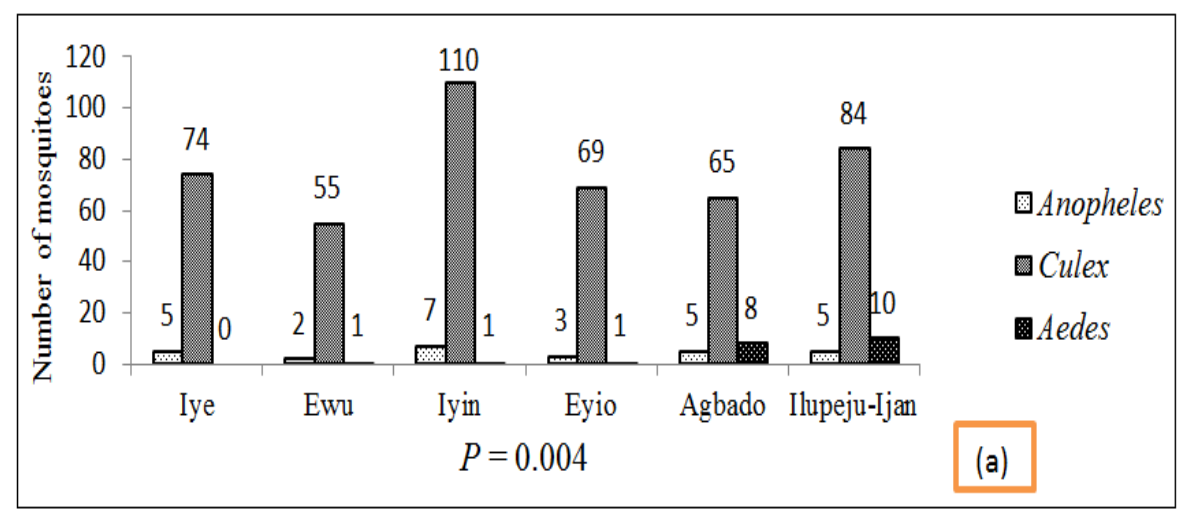




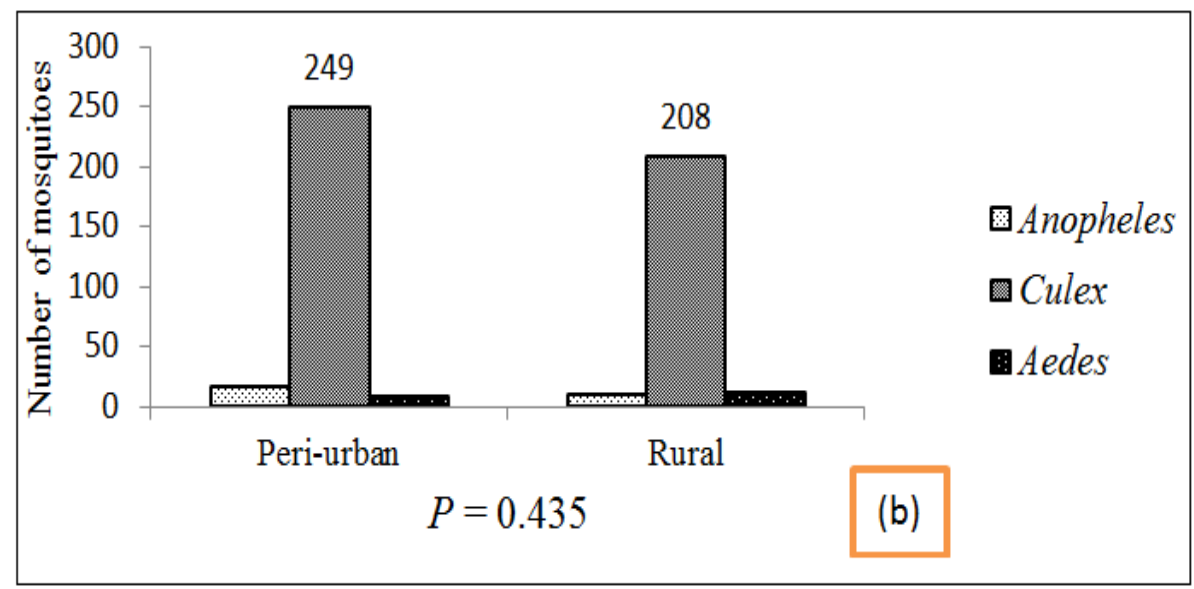

Fig-2: Abundance of mosquito genera collected outdoors (a) Chart showing the six communities (b) Chart showing community types

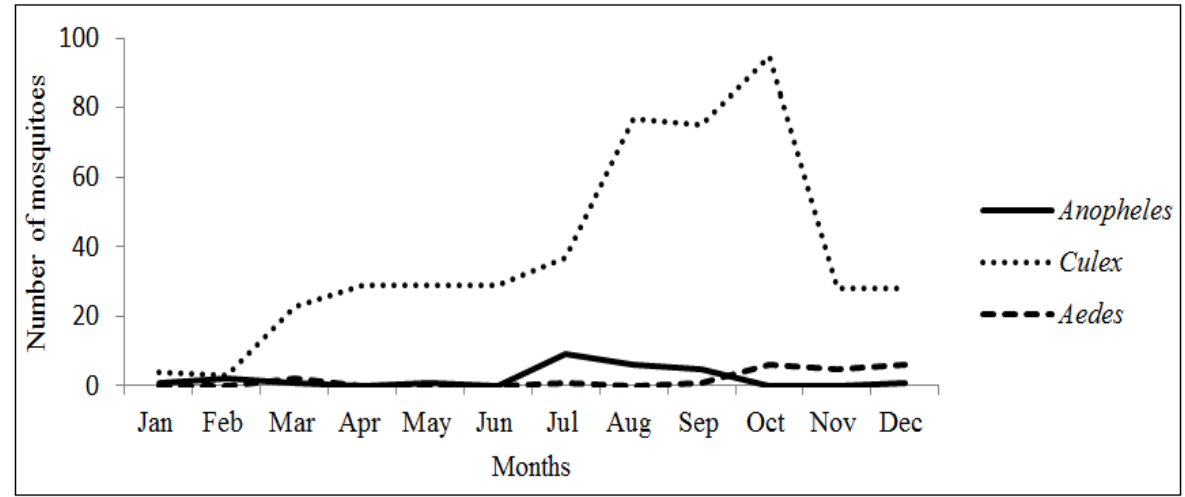

Fig-3: Monthly Distribution of mosquito genera collected in the study communities $(P=0.001)$

\section{CONCLUSION}

The collection of the adult mosquitoes in this study suggests that the environmental conditions of these communities support the continual breeding and survival of the mosquitoes especially Culex mosquitoes. The availability of these mosquito vectors at dusk when people of these communities may stay outdoors is an indication that the people in these communities may be at risk of mosquito borne diseases.

\section{Ethical Approval}

Ethical approval (EKSUTH/A67/07/002) was obtained from Ethics and Research Committee, Ekiti State University Teaching Hospital, Ado-Ekiti, Ekiti State, Nigeria.

Conflict of interest: The author declares no conflict of interest.

\section{REFERENCES}

1. Sogoba, N., Doumbia, S., Vounatsou, P., Baber I., Keita, M., Maiga, M., Traore, S.F., Toure, A., Dolo, G., Smith, T., \& Ribeiro, J. M. C. (2007). Monitoring of Larval Habitats and Mosquito Densities in the Sudan Savannah of Mali: Implication for Malaria Vector Control. American Journal of Tropical Medicine and Hygiene, 77(1):82-88.
2. Tandina, F., Doumbo, O., Yaro, A. S., Traoré, S. F., Parola, P., Robert, V. (2018). Mosquitoes (Diptera: Culicidae) and mosquito-borne diseases in Mali, West Africa. Parasites \& Vectors, 11, 467.

3. CDC. (2015). CDC Malaria Parasites-Biology, CDC: Malaria. U.S. Centers for Disease Control and Prevention. Retrieved 28 December 2015.

4. Johnston, L. D., O'Malley, P. M., \& Bachman, J. G. (1991). Drug use among American High School Seniors, college students and young adults, 1975-1990. U.S. Department Of Health And Human Services Public Health Service. DHHS Publication No. (ADM) 91-1813.

5. Ayorinde, D. (1994). Controlling development at the urban fringe: A case study of Ibadan, Nigeria. In: Urban Management and Urban Violence in Africa, Vol 2 (ed) by I.O. Albert, J. Adisa, T. Agbola, and G. Herault, IFRA-Ibadan.

6. Agbodike, C. C. (2010). Population growth and the dilemma of rural life and economy in Nigeria. Unizik Journal of Arts and Humanities, 11(1):121.

7. Gillies, M. T., \& de Meillon, B. (1968). The Anophelinae of Africa south of the Sahara (Ethiopian Zoogeographical Region, $2^{\text {nd }}$ edn). Publications of the South African Institute for Medical Research, 54, 1-343. 
8. Leal, W. S. (2014). The enigmatic reception of DEET-the gold standard of insect repellents. Current Opinion Insect Science, 6:93-98.

9. Okorie, P., Popoola, K. O. K., Awobifa, O. M., Ibrahim, K. T., \& Ademowo, G. O. (2014). Species composition and temporal distribution of mosquito populations in Ibadan, Southwest Nigeria. Journal of Entomology and Zoology Studies, 2(4):164-169.

10. Amaechi, E. C., Ukpai, O. M., Ohaeri, C. C., Ejike, U. B., Irole-Eze, O. P., Egwu, O., \& Nwadike, C. C. (2018). Distribution and seasonal abundance of Anopheline mosquitoes and their association with rainfall around irrigation and nonirrigation areas in Nigeria. UNED Research Journal/Cuadernos de Investigación, 10(2):267272.

11. Nchoutpouen, E, Talipouo, A., Djiappi-Tchamen, B., Djamouko-Djonkam, L., Kopya, E., Ngadjeu, C. S., Doumbe-Belisse, P., Awono-Ambene, P., Kekeunou, S., Wondji, C. S., \& AntonioNkondjio, C. (2019). Culex species diversity, susceptibility to insecticides and role as potential vector of Lymphatic filariasis in the city of Yaoundé, Cameroon. Plos/Neglected tropical diseases. doi.org/10.1371/journal.pntd.0007229.

12. Bates, M. (1949). The natural history of mosquitoes. New York. The Macmillan Company.

13. Gouge, D. H, Smith, K. A., Olson, C., \& Baker, P. (2001). Mosquitoes. The University of Arizona, College of Agriculture and Life Sciences, Tuscon, Arizona, 85721.

14. Sattler, M., Mtasiwa, D., Kiama, M., Premji, Z., Tanner, M., Killeen, G., \& Lengeler, C. (2005).
Habitat characterization and spatial distribution of Anopheles sp. mosquito larvae in Dar es Salaam (Tanzania) during an extended dry period. Malaria Journal, 4(1), 4. pmid:15649333

15. Kitching, R. L. (2001). Food webs in phytotelmata: bottom-up and "top-down" explanation for community structure. Annual Review of Entomology, 46:729-760.

16. Okorie, T. G. (1978). The breeding site preferences of mosquitoes in Ibadan, Nigeria. Nigerian Journal of Entomology, 1:71-80.

17. Mutero, C. M., Nga'ang'a, P. N., Wekoyela, P., Githure, J., \& Konradsen, F. (2004). Ammonium sulphate fertilizer increases larval populations of Anopheles arabiensis and culicine mosquitoes in rice fields. Acta Tropica, 89:187-192.

18. Ndenga, B. A., Mutuku, F. M., Ngugi, H. N., Mbakaya, J. O., Aswani, P., \& Musunzaji, P. S. (2017). Characteristics of Aedes aegypti adult mosquitoes in rural and urban areas of western and coastal Kenya. PLoS ONE, 12(12):e0189971.

19. Offiong, R. A., Atu, J. E., Njar, G. N., \& Amuyou, U. A. (2008). Problem and prospect of poor drainage system in Calabar, Nigeria. Global Journal of Social Sciences, 7(2):121-127.

20. Olayemi, I. K. (2008). Survivorship of Anopheles gambiae in relation to malaria transmission in Ilorin, Nigeria. Online Journal of Health and Allied Sciences, 7:3-7.

21. Utah, E. C., Wokem, G. N., \& Okonofua, C. (2013). The abundance and biting pattern of Culex quinquefasciatus Say (Culicidae) in the coastal region of Nigeria. ISRN Zoology, 1-7. 